\title{
A Room to Grow: The Residential Density-Dependence of Childbearing in Europe and the United States
}

\author{
Nathanael Lauster \\ Department of Sociology \\ University of British Columbia \\ E-mail: nlauster@interchange.ubc.ca
}

\begin{abstract}
It is argued that cultural processes linked to the demographic transition produce new density-dependent fertility dynamics. In particular, childbearing becomes dependent upon residential roominess. This relationship is culturally specific, and that the cultural nature of this relationship means that professional and managerial classes are likely to be particularly influenced by residential roominess, while immigrants are less likely to be influenced. Hypotheses are tested linking residential roominess to the presence of an "own infant" in the household using census data from the Austria, Greece, Portugal, Spain, and the United States. Roominess predicts fertility in all countries, but to differing degrees.
\end{abstract}

Key Words: Housing, fertility, culture, density-dependence 


\section{Résumé}

Je soutiens dans cet article que les processus culturaux qui sont liés à la transition démographique produisent de nouvelles dynamiques de fécondité dépendantes à la densité. En particulier, la procréation devient dépendante de la spaciosité résidentielle. Cette relation est culturellement spécifique et je maintiens que le caractère culturel de cette relation indique que les classes professionnelles et gérantes ont plutôt tendance à être plus influencées par la spaciosité résidentielle, tandis que les immigrants ont tendance à moins l'être. J'ai testé mes hypothèses reliant la spaciosité résidentielle à la présence d'un "propre enfant" dans les ménages en me servant des données provenant de l'Autriche, de la Grèce, du Portugal, de l'Espagne et des États-Unis. La spaciosité détermine la fécondité dans tous les pays mais à différents degrés.

Mots-clés: Logement, fécondité, culture, dépendant de la densité

\section{Introduction}

Historical demographers forward the notion that homeostatic mechanisms linking population growth (especially through nuptiality, but also fertility and mortality) to population density have played an important role in the course of population history (Lee 1987; Livi-Bacci 2007). Higher density limits population growth, while lower density encourages it. By and large, these mechanisms are presumed to be agrarian in nature, to have been negotiated by different cultures differently, and to have disappeared with the Industrial Revolution as the availability of agricultural land became less and less salient to household economies. Yet increasingly, research on the intersections of housing and fertility has suggested new mechanisms by which densitydependence might occur. To the extent that such mechanisms do exist, they are likely to be rooted in new conceptions of the residential space required to perform the role of parenthood properly. As such, new cultural constructions of appropriate residential space are likely to result in density-dependent regimes of population regulation where fertility is positively influenced by the relative roominess of housing. 
Several studies provide support for the existence of mechanisms linking housing structure to fertility in Columbia (Felson and Solauns 1975), Finland (Kulu and Vikat 2008), and Iran (Paydarfar 1995). These studies find that living in apartments, which tend to be smaller in size than detached dwellings, tends to reduce fertility. Curry and Scriven (1979) found that the effect of structure (apartment vs. detached) was less important than the effect of rooms in a Midwestern city in the USA. A number of studies have also looked at the relationships between housing tenure and fertility in the USA (Krishnan 1995), Great Britain (Murphy and Sullivan 1985), West Germany and the Netherlands (Mulder and Wagner 1998 and 2001), with mixed results, arising from differing interpretations of the timing of transitions and the costs of ownership relative to childbearing. Generally, the evidence seems to indicate that larger dwellings are more conducive to childbearing, but specifics are difficult to interpret, since tenure, structure, and roominess of housing are all closely interrelated in most contexts, making it difficult to separate relationships with fertility. Likewise, assessing the causal direction between housing characteristics and fertility has proven difficult, even when the timing of moves and childbearing are taken into account. Few studies have explicitly examined the effects of relative roominess (or inversely, crowding) on fertility. One exception is the Gove, Hughes and Galle study (1975), which found crowding to be positively (and pathologically) correlated with fertility in Chicago. These findings were later criticized by Choldrin (1978) for pathologizing fertility and confusing causality, and by Loftin and Ward (1983) for ignoring spatial autocorrelations. This research takes the opposite position of Gove, et al. Instead of increasing fertility in the current cultural settings of North America and Europe, crowding is likely to reduce fertility.

There are strong reasons to support that the relative roominess of housing positively influences fertility in many contexts, but it is important to note that the relationship is the product of cultural change, and is hence culturally contingent. Universal, objective and biological limit to residential density is not supported. Indeed, positing such a relationship would be untenable given the joint occurrence of high residential crowding and high fertility witnessed through most of human history up to the present. Instead, research indicates that the power of crowding is subjective rather than objective, and is hence likely to be culturally produced (Edwards et al. 1994; Fuller et al. 1996; Lauster and Tester 2010; Ward 1999). This implies that any mechanisms making fertility behaviour dependent upon residential density are likely to have arisen through cultural change. 
The cultural processes capable of installing new density-dependent fertility regulation mechanisms are likely multifaceted. Three possible interlocking explanations with substantial potential for generalization are discussed, including the expansion of invidious distinction accompanying the rise of a bourgeois class, the expansion of health reform bureaucracies accompanying the rise of the state, and the expansion of interpersonal staging requirements accompanying the rise of modernity. Incidentally, It is suggested that three prominent explanations for the demographic transition discussed in the literature; capitalist industrialization, state development, and modernization, are likely to derive some of their explanatory power through the creation of new density-dependent mechanisms regulating fertility.

Capitalist industrialization tends to create new wealth, tearing down old ascribed status barriers, and building new cultures founded upon invidious distinction in the process (Frykman and Löfgren 1987; Gillis 1996). New wealth tends to be urban, and those with money are also able to secure more residential space, a substantial portion of which becomes used as staging material for the display of privilege (Frykman and Löfgren 1987). This sets up a low-density model for residential living likely to be emulated by those aspiring to achieve respectability. Residential crowding, in turn, becomes stigmatizing by its association with poverty. A display of roominess is likely to be particularly important for those with the highest status. Given constraints on space, one way to insure a modicum of roominess is to constrain fertility.

The expansion of the state possibly sets the stage for and accompanies the demographic transition (Watkins 1990). A significant part of the expansion of the state includes bureaucratic attempts to monitor and regulate the health of citizens. Public health bureaucracies institute reforms ostensibly aimed at improving common welfare and combating social blight. Residential crowding becomes associated with disease, and is frequently a target of such bureaucracies. The state may take actions to actively discourage crowding, including threatening to disband households violating normative standards in the name of social welfare (Lauster and Tester 2010). One way to prevent states from disbanding households is to constrain fertility in accordance with rooms available.

Finally, new cultural mechanisms linking fertility to density may arise from the changing conditions of human interaction. The movement from rural to urban living also creates the context for a decline in Durkheim's mechanical solidarity, and a rise in organic solidarity marked by the adoption of multiple social roles. The separation of work and home similarly creates shifting identities. In this way, the multiplicity of social roles extends within the family, where partners, parents, and 
children all need backstage space to prepare their familial performances and assemble independent identities (Gillis 1996; Goffman 1959). Overall, privacy becomes increasingly important (War 2000), and individuals become increasingly motivated to preserve backstage space for themselves in the home by limiting their household size relative to housing space. In particular, separate rooms become seen as important for couples, and for children, especially if they differ in gender.

The impact of the cultural processes described above is likely to vary by cultural centrality and integration. Following Frykman and Löfgren's consideration of the "culture-building" nature of the professional and managerial classes, the privileged classes are likely to be most influenced by roominess. They are the ones likely to set the standards for the rest of the population, through the process of using their own housing as a stage to demonstrate social distinction. The professional and managerial classes are also the most integrated with the state, and arguably offer the greatest demand for privacy. By contrast, immigrants are likely the least integrated in the cultural processes making roominess important. They are likely the least impressed with the importance of maintaining privileged living standards (being able to make alternative comparisons from their home country), and they are least integrated with the state. Less is theoretically discernible about immigrant evaluations of privacy.

In more developed countries, the intersecting cultural changes discussed above are particularly likely to have arisen together. As a result, relative roominess of dwellings is likely to increase fertility. A wide variety of more developed (and developing) countries are now experiencing below replacement level fertility. This may be, in part, due to the rise in the importance of roominess. According to Population Reference Bureau estimates, Europe's TFR in 2008 averaged 1.5, with Northern Europe maintaining higher rates (though still generally below replacement level), and Southern Europe lower rates. Canada is close to the European average, with a TFR of 1.6. The USA, by contrast, has managed to maintain a TFR of 2.1, closely approximating replacement rates. To the extent that the relative roominess of housing boosts fertility, some of the difference in fertility rates between the United States and many other developed countries might be explained by larger dwelling sizes in the United States.

A simple way to estimate the relationship between relative roominess and fertility is provided in the rest of the paper. Further exploration of the evidence using available census data with large sample sizes for the United States, Austria, Greece, Portugal, and Spain is also presented. The latter four European countries all have particularly low fertility relative to the USA (estimated between 1.3 and 1.4 for 2008). 
Nevertheless, they differ in important ways, both from the USA and from each other.

Austria and the USA both have high rates of household independence for women (as heads or partners), but women in Austria are more likely to be working, less likely to own their own homes, and more likely to be in cohabiting partnerships. Greece and the USA have similar levels of ownership for household heads or partners, but Greek women are less likely to be heads or partners. Women in Greece are also more likely to be married and less likely to be employed. Portuguese women have similar rates of employment as American women, but they are less likely to be household heads or partners, and more likely to be owners if they become heads or partners. Spanish women have similar marriage rates as Americans, but are less likely to be employed, less likely to be a head or partner of a household, and much more likely to own their home if they become a household head. These patterns are summarized in Table 1.

Notably, Table 1 builds on Mulder and Billari's (2010) typology of European and North American housing markets. Mulder and Billari (2010) make the assertion that Austria, Greece, Portugal and Spain all have limited mortgage financing compared to the United States (and elsewhere), making transitions to home ownership difficult and heavily reliant upon savings, family transfers, and family inheritances. Nevertheless, they argue that the USA, Austria and Portugal have relatively accessible rental markets compared with Spain and Greece, where rental markets are less developed. As a result, they suggest it makes sense that the USA, Austria, and Portugal would all have higher household headship rates than Spain and Greece, where beginning a new household and starting a new family are very difficult. According to Table 1, Portugal is only marginally distinct from headship patterns for Spain and Greece, and home ownership rates in Greece are below those for Portugal. Otherwise all data fit well with Mulder and Billari's (2010) interpretation. All data are from the IPUMS dataset for women age 1544 living in households in 2000 (USA) or 2001 (all other countries), except for the Total Fertility Rate, which comes from the Population Reference Bureau estimates for 2008.

Overall, the cases of the USA, Austria, Greece, Portugal and Spain illustrate some of the key similarities and differences between countries which might prove useful in exploring fertility dynamics. These countries also provide their census data to the IPUMS dissemination project, and contain in their census data important information on housing, including number of rooms per household and number of household members per household. These two variables can be 
combined to construct a measure of relative roominess. For the rest of this paper, five broad hypotheses are explored.

Hypothesis 1: Relative roominess will be associated with a greater likelihood of having a child in all countries. The follows from the set of cultural forces associated with development operating in the European and North American countries to install a new set of residential densitydependent mechanisms for population regulation.

Hypothesis 2: The association between relative roominess and having a child will be influenced by immigration. Those foreign-born will be less likely to feel culturally constrained by the effects of roominess on fertility.

Hypothesis 3: The association between relative roominess and having a child will be influenced by social class. Those in the leading class will be more likely to feel culturally constrained by the effects of roominess on fertility.

Hypothesis 4: The association between relative roominess and having a child may explain some portion of the difference between the American and European fertility patterns.

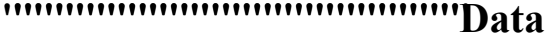

The data for this study come from the IPUMS-International dataset compiled by researchers at the University of Minnesota (Minnesota Population Center 2010). Microdata samples of census data from the USA (2000), Austria (2001), Greece (2001), Portugal (2001), and Spain (2001) are provided for public use. Samples of non-institutionalized women, age 15-44 are used is this analysis. Sample density is $0.5 \%$ in the United States, and 5\% in all other samples, providing samples of roughly similar sizes (Spain and the USA remaining somewhat larger). For analyses, samples were further restricted to married or cohabiting women living as household heads or the partners of household heads. This insures that women included in the study were likely to have some control over (and be able to respond to) the fit between household and housing. At the same time, this regrettably leaves out of the analysis the substantial number of women, especially in Greece, Portugal and Spain, who are not married, cohabiting, householders or householder partners. Differing rates of cohabitation, marriage and access to headship are arguably major explanations for fertility differentials between countries. 
Table 1

Childbearing, Family Household

and Employment Trends for Women Aged 15 - 44

in Five Countries, IPUMS Data Sets: 2000/2001

\begin{tabular}{lccccc}
\hline \multicolumn{1}{c}{ Variable } & USA & Austria & Greece & Portugal & Spain \\
& & & & & \\
\hline TFR 2008 & 2.1 & 1.4 & 1.4 & 1.3 & 1.4 \\
\hline & & & Percent & & \\
With Infant & 6.1 & 4.3 & 4.3 & 4.8 & 3.9 \\
Married & 47.1 & 42.9 & 53.1 & 51.5 & 45.0 \\
Cohabiting & 3.8 & 10.1 & 1.3 & 6.0 & 4.5 \\
Divorced & 12.5 & 8.7 & 4.8 & 4.1 & 3.7 \\
Single & 36.5 & 38.3 & 40.7 & 38.4 & 46.8 \\
Employed & 63.9 & 70.6 & 45.9 & 63.1 & 43.7 \\
Household Heads & 70.4 & 70.4 & 58.9 & 60.0 & 54.6 \\
Home Owners & 58.7 & 48.2 & 61.8 & 74.4 & 78.4 \\
& & & & & \\
\hline
\end{tabular}

Source: TFR data from 2008 Population Reference Bureau estimates.

A variety of variables were created from IPUMS files for use in this study. Fertility was approximated using the presence of an "own" infant in the household (Malenfant and Belanger 2006). This provides a point estimate of fertility appropriate for cross-sectional data. Overall, this estimate is downwardly biased to a slight extent due to the effects of infant mortality and the timing of listing household members for the census. If an infant (less than one year old) is present in the household linked to the woman in the study, this variable is a one, otherwise it is a zero. This allows for a logistic regression model to be used to estimate the relationships between having a child and roominess net of control variables.

For the measure of relative roominess in a household, the total number of household members (subtracting one if an infant is recorded in the household) was subtracted from the total number of rooms. The measure of number of rooms was relatively standardized across samples. All samples excluded bathrooms. Kitchens were likewise excluded from the Austrian, Greek, and Portuguese samples. Kitchens were included in 
the Austrian, Greek, and Portuguese samples. Kitchens were included in Spain if they measured at least four square meters. Kitchens were included in the USA, but "half-rooms" were not. As an adjustment, one room was subtracted from the American and Spanish samples to make measurements of total rooms more equivalent. All samples were constricted to no more than 9 rooms, following USA standards. Correspondingly, roominess ranged from -21 rooms to +8 .

A number of control variables are also included. Home ownership information is available in all samples, and is often associated with roomier dwellings. Home ownership is separated by including it as a separate dummy variable. Age and age-squared are included in the analysis since age is associated both with underlying fecundity, with agerelated childbearing norms, and with the type of housing one has access to.

Separate measures of relationship status are also provided. Relationships can influence housing type, number of household members, and sexual exposure to risk of childbearing. Data on marital status are provided for all samples. Data on non-marital cohabiting status are derived from the relationship to household head variable (indicating "partner") and the consensual union variable where it is available (available for Austria, Portugal, and Spain). For all countries those indicating they are partners of the household head without listing themselves as married are assumed to be cohabiting. This may leave out some women who list themselves (rather than their partners) as household heads, but are also cohabiting in the USA and Greece. I also provide a dummy variable indicating whether or not a woman has an employed partner. Finally, a count of the number of unrelated individuals in a household is provided. This serves as a check to measure how roommates might influence fertility, and also influence relative roominess.

Education and occupation measure different aspects of social status, access to monetary resources, and cultural capital. These can have influences on access to various types of housing, and could also have independent influence on fertility. Education is measured in a fashion similar to the standardized coding of educational attainment in the IPUMS dataset. Lower education is distinguished from completing secondary education. This, in turn, is distinguished from completing some college or related post-secondary technical training. Finally, university degrees are distinguished from other education levels. Overall, the differing educational systems for different countries make cross-national comparisons by education difficult. For occupation, professional and managerial work is distinguished from other white collar jobs, which in turn are distinguished from blue collar and other 
jobs using a standardized IPUMS coding scheme. The occupations of both women and their partners are used. If either partner fits into a professional or managerial occupation category, then a woman is coded as belonging to the professional and managerial classes. Failing that, if either partner holds a white collar job, then a woman is coded as white collar. Those women allocated to neither of these classes are assumed to be located in the remaining working classes. Correspondingly, professional and managerial oriented women are assumed to occupy the highest status group, and may be distinguished as "culture builders" in the way Frykman and Löfgren (1989) use the term.

Immigrant women may have different orientations to childbearing and may experience different feelings of crowding as a product of different cultural orientations. Immigrant women are denoted in all samples as foreign-born. Immigrant women may be distinguished as having different cultural responses to roominess. In conclusion, employment for women is also measured. Employed women might be able to afford more roomy housing, but might also face substantially more difficult infant caregiving arrangements. The means of variables for each sample are summarized in Table 2.

\section{Results}

Separate results of logistic analysis models for each country are included in Table 3. Odds ratio effects on the likelihood of reporting an own infant in the household are estimated for each variable. For Austria, Greece, Portugal, and Spain, odds ratio effects are bolded where a completely interacted fixed effects model including all countries indicates significant effect differences from the United States.

Overall, control variables predict childbearing much as expected. Age has a curvilinear relationship to fertility between the ages of 15-44, on top of a slight negative effect everywhere except Spain. Children tend to come earlier to women in the USA than in Europe. Being in a cohabiting relationship relative to marriage has a generally negative effect on fertility, except in Portugal. The effect of being in a cohabiting relationship is most strikingly negative in Greece, where comparatively very few infants are living with unmarried couples. Having a partner who is employed is important and boosts the likelihood of childbearing in the USA, Greece, and Spain. The number of unrelated housemates one lives with tends to have no effect on fertility, except in the USA and Spain, where it oddly boosts childbearing. This may be associated with the use of live-in nannies in these countries. 
The effects of education level vary between countries. In the USA and Austria, completed education has a curvilinear sort of effect. Relative to those completing secondary education, those with lower levels of education, and those with higher levels of education (some college or above) are more likely to have an infant in the house, indicating higher fertility levels. By contrast, the relationship between education and fertility in Greece and Spain looks quite linear. The higher a woman's education level, the more likely she is to have a child. In Portugal, those with less than secondary education are less likely to have a child. Being currently in school consistently reduces fertility in all countries except for Greece, where it oddly seems to have the opposite effect.

Foreign-born women tend to have higher fertility than the nativeborn population in the United States and Austria. Elsewhere, foreignborn and native fertility patterns look much the same. Being currently employed for women has a negative effect on having an infant in the household everywhere except Austria. Outside of Austria, new mothers often leave work after their children are born, meaning the true causal relationship is likely the opposite of that modeled here. Within Austria, work-family leave and childcare arrangements likely create very different conditions, encouraging mothers to continue working and encouraging working women to become mothers.

Occupational class has a striking effect on fertility everywhere except Greece. Women in the professional and managerial classes, or partnered with someone in the professional and managerial classes, are particularly likely to have an infant in the household relative to those in the blue collar and working classes. Women associated with other white collar classes also demonstrate higher rates of childbearing than those in the blue collar and working classes in the USA and Austria, but not Spain or Portugal.

Finally, relative roominess of housing has a strongly positive effect on fertility in all countries. The positive effects of roominess are independent of ownership. Indeed, controlling for roominess, home ownership exerts a negative effect on fertility in the USA, Austria, and Greece. This fits with the expectation that the costs of buying a home might compete with the costs of having a child. Overall, the effects of roominess on fertility provide support for hypothesis one. New residential density-dependent mechanisms regulating population growth through limiting fertility seem to be operating in both Europe and North

America. Nevertheless, while the effects of roominess on fertility are consistently positive across countries, they also differ in strength. 
Table 2

Variable Summaries and Sample Description, Married or Cohabiting Non-Institutionalized Women Householders or Householder Partners, Age 15-44 in Five Countries (in percent)

\begin{tabular}{l|c|c|c|c|c}
\hline \multicolumn{1}{c|}{ Variable } & $\begin{array}{c}\text { USA } \\
\mathbf{2 0 0 0}\end{array}$ & $\begin{array}{c}\text { Austria } \\
\mathbf{2 0 0 1}\end{array}$ & $\begin{array}{c}\text { Greece } \\
\mathbf{2 0 0 1}\end{array}$ & $\begin{array}{c}\text { Portugal } \\
\mathbf{2 0 0 1}\end{array}$ & $\begin{array}{c}\text { Spain } \\
\mathbf{2 0 0 1}\end{array}$ \\
\hline \hline With Infant & 9.1 & 6.7 & 7.8 & 7.5 & 7.5 \\
Age & 34.1 & 34.5 & 34.6 & 34.1 & 35.1 \\
Married & 92.2 & 81.4 & 97.3 & 89.8 & 90.7 \\
Cohabiting & 7.8 & 18.6 & 2.7 & 10.2 & 9.3 \\
Employed Partner & 88.5 & 94.4 & 89.5 & 92.1 & 81.6 \\
Unrelated Individuals & 5.0 & 1.0 & 5.0 & 1.0 & 5.0 \\
Lower Education & 6.5 & 26.1 & 37.5 & 69.9 & 54.5 \\
Secondary Education & 26.5 & 50.8 & 37.2 & 16.9 & 26.5 \\
Some College & 33.2 & 17.3 & 11.7 & 0.3 & 9.4 \\
University & 27.1 & 5.8 & 13.6 & 12.9 & 9.6 \\
In School & 8.5 & 1.2 & 1.4 & 3.7 & 7.1 \\
Foreign-Born & 17.4 & 17.1 & 16.9 & 9.1 & 7.1 \\
Employed & 67.2 & 75.6 & 51.9 & 73.3 & 48.1 \\
Professional/Managerial & 40.7 & 24.3 & 26.3 & 20.3 & 26.0 \\
White Collar & 45.4 & 48.4 & 28.5 & 37.9 & 37.5 \\
Working Class & 13.9 & 27.3 & 45.2 & 41.8 & 36.6 \\
Extra Room & 1.2 & 1.2 & -0.3 & 0.4 & 0.5 \\
Home Owner & 70.0 & 56.2 & 65.2 & 76.3 & 80.8 \\
6ample N & 60,378 & 65,269 & 67,932 & 252,877 & 205,654 \\
\hline & & & & & \\
\hline
\end{tabular}


Overall, the positive effects of an extra room on fertility are strongest in Greece, and weakest in Spain and the USA. Cultural differences seem to operate through a variety of variables in this analysis. Roominess is no exception. Culture influences the ways residential density-dependent mechanisms regulating population growth operate.

In Table 4, evidence of the divergence in roominess between the general populations of each country is provided, the foreign-born, and the professional and managerial classes. As expected, the professional and managerial classes maintain the highest standard of roominess in each country, averaging roughly an extra half room compared to national means. By contrast, the foreign-born have fewer rooms than the national mean in nearly every country. The disparity between the foreign-born and the population as a whole is greatest in the United States (where the foreign born average almost two fewer rooms), and smallest in Portugal (where the foreign-born actually average about 0.1 extra rooms more than the population as a whole). In each country, the variation in extra rooms is greatest for the foreign-born.

Table 5 shows the results of models interacting foreign-born and professional or managerial class with roominess. If the way roominess effects fertility is culturally contingent, then the foreign-born population may be less likely to feel the effects of roominess. Crucially, the way immigrants respond to roominess may correspond to where they are from, is not considered separately here. Nevertheless, the overall effects of roominess are likely to differ for foreign-born populations, and to the extent the foreign-born come from less developed countries, they are likely less responsive to roominess. In the results from table four, this appears to be the case for all countries, though the interactive effect is only marginal for Portugal. Overall, these findings provide broad support for hypothesis two.

The effects of roominess for Professionals and the Managerial classes, by contrast, should be even stronger than for the rest of the population. They should be leading the cultural changes making roominess an important factor for fertility. Table 5 results support a positive effect for the interaction between professional/managerial class and roominess in the USA, Austria, and Portugal. Roominess matters more for the privileged occupational classes, providing substantial support (if limited in scope) for hypothesis three. 
Table 3

Effects on Likelihood of Own Infant in Household, Married or Cohabiting Non-Institutionalized Women Householders or Householder Partners Aged 15 - 44 Years in Five Countries

\begin{tabular}{|c|c|c|c|c|c|}
\hline Variable & $\begin{array}{l}\text { USA } \\
2000\end{array}$ & $\begin{array}{c}\text { Austria } \\
2001\end{array}$ & $\begin{array}{c}\text { Greece } \\
2001\end{array}$ & $\begin{array}{c}\text { Portugal } \\
2001\end{array}$ & $\begin{array}{c}\text { Spain } \\
2001\end{array}$ \\
\hline Age & $0.94 * * *$ & $0.94 * * *$ & $0.97 * * *$ & $0.97 * * *$ & $1.02 * * *$ \\
\hline $\mathrm{Age}^{2}$ & $0.99 * * *$ & $0.99 * * *$ & $0.99 * * *$ & $0.99 * * *$ & $0.99 * * *$ \\
\hline Cohabiting & $0.51 * * *$ & $0.61 * * *$ & $0.13 * * *$ & $1.09+$ & $0.72 * * *$ \\
\hline Employed Partner & $1.09 *$ & 1.01 & $1.4^{* * *}$ & 1.03 & $1.05 *$ \\
\hline Unrelated Indivdual & $1.22 * * *$ & 0.95 & 1 & 0.88 & $1.18^{* * *}$ \\
\hline Lower Education & $1.23 * * *$ & $1.1+$ & $0.83 * * *$ & $0.83 * * *$ & $0.82 * * *$ \\
\hline Some College & $1.18^{* * *}$ & $1.16^{* *}$ & $1.34 * * *$ & 1.54 & $1.26^{* * *}$ \\
\hline University & $1.47 * * *$ & $1.72 * * *$ & $1.77 * * *$ & 1.1 & $1.52 * * *$ \\
\hline In School & $0.45^{* * *}$ & $0.31 * * *$ & $2.11 * * *$ & $0.48 * * *$ & $0.29 * * *$ \\
\hline Foreign-Born & $1.24 * * *$ & $1.41 * * *$ & 1.02 & 1.01 & $1.05 * * *$ \\
\hline Employed & $0.42 * * *$ & $1.24 * * *$ & $0.69 * * *$ & $0.68 * * *$ & $0.54 * * *$ \\
\hline Professional/Managerial & $1.19^{* * *}$ & $1.2 * *$ & 0.99 & $1.15^{* *}$ & $1.25^{* * *}$ \\
\hline White Collar & $1.17 * * *$ & $1.15^{* *}$ & 0.95 & 1 & 1.02 \\
\hline Extra Rooms & $1.15^{* * *}$ & $1.2 * * *$ & $1.31 * * *$ & $1.19 * * *$ & $1.16^{* * *}$ \\
\hline Home Owner & $0.93 * *$ & $0.89 *$ & $0.89 * * *$ & 0.94 & 0.97 \\
\hline
\end{tabular}

$+\mathrm{p}<0.10, * \mathrm{p}<0.05, * * \mathrm{p}<0.01, * * * \mathrm{p}<0.001$

Bold significantly different from USA results in fully interacted fixed effects model $(\mathrm{p}<0.05)$. 
Table 4

Subpopulation Differences in Extra Rooms

for Married or Cohabiting Non-Institutionalized

Women Householders or Householder Partners Aged 15 - 44 Years by Country

\begin{tabular}{lccccc}
\hline & USA & Austria & Greece & Portugal & Spain \\
& 2000 & 2001 & 2001 & 2001 & 2001 \\
& & & & & \\
Overall & 1.2 & 1.2 & -0.3 & 0.4 & 0.5 \\
Mean & 2.2 & 1.6 & 1.5 & 1.5 & 1.7 \\
Std. Dev. & & & & & \\
Foreign Born & -0.6 & 0.2 & -0.7 & 0.5 & -0.2 \\
$\begin{array}{l}\text { Mean } \\
\text { Std. Dev. }\end{array}$ & 2.6 & 1.8 & 1.6 & 1.7 & 2.3 \\
$\begin{array}{l}\text { Professional/Managerial } \\
\text { Mean }\end{array}$ & 1.9 & 1.6 & 0.2 & 1.0 & 0.9 \\
Std. Dev. & 2.0 & 1.6 & 1.4 & 1.5 & 1.5 \\
& & & & & \\
\hline
\end{tabular}

In order to visually demonstrate and explore the variation in the effects of roominess across different countries for different groups, an estimate of the simulated risks of having an own infant in the household is based on model results from Table 5. The simulation assumes that women are age 25 , married, employed with an employed partner, have completed some college but are currently not in school, and are homeowners with no unrelated household members living in the household. For a base sense of probabilities in each country, the simulation assumes women are native-born and blue collar. The effects of extra rooms for these women are compared to foreign-born and blue-collar women, as well as native-born and professional/managerial women, as per the interactive models. Risks of having an own infant in the household are estimated at the mean number of extra rooms for each group (see Table 4). This is compared to a baseline risk of having an own infant for those with one extra room. In Figure 1 portrays the percent difference in the simulated risk of having an own infant in the household for those at the mean extra rooms for their group relative to those with exactly one extra room. This provides for a visual interpretation of the size of the effect of 
roominess for each group, incorporating group-level means and differences in effect sizes.

Overall, those living in the United States and Austria are likely to have an extra room or more. As a result, they experience a boost in the likelihood of having children relative to those living in Portugal, Spain, or (especially) Greece. The lack of extra rooms in these countries depresses overall fertility, explaining some of the difference between American and European childbearing patterns. This provides qualified support for hypothesis four. While the greater availability of extra rooms in the USA is likely to help explain fertility differences between America and Greece, Portugal, and Spain, it provides little traction in explaining differences between American and Austria.

\section{Table 5}

Interaction Effects on Likelihood of Own Infant in Household for Married or Cohabiting Non-Institutionalized Women Householders or Householder Partners Aged 15 - 44 Years by Country (Odds Ratios Reported)

\begin{tabular}{lccccc}
\hline & USA & Austria & Greece & Portugal & Spain \\
& 2000 & 2001 & 2001 & 2001 & 2001 \\
$\begin{array}{l}\text { Foreign- } \\
\text { Born }\end{array}$ & $1.26 * * *$ & $\mathbf{1 . 4 9} * * *$ & $\mathbf{1 . 0 2}$ & $\mathbf{1 . 0 6}$ & $\mathbf{1 . 1 3} * * *$ \\
$\begin{array}{l}\text { Professional } \\
\text { Extra Rooms }\end{array}$ & $1.12 * *$ & 1.07 & 0.99 & 1.07 & $\mathbf{1 . 2 5} * * *$ \\
$\begin{array}{l}\text { Foreign- } \\
\text { Born }\end{array}$ & $0.93 * * *$ & $0.93 * *$ & $0.93 * *$ & $0.95+$ & $\mathbf{0 . 8 5 * * *}$ \\
Professional & $1.05 * * *$ & $1.07 *$ & $1.33 * * *$ & $1.18 * * *$ & $\mathbf{1 . 1 9 * * *}$ \\
& & & 1 & $1.06 * *$ & $\mathbf{1}$ \\
\hline
\end{tabular}

Note: Models include all control variables from previous model.

$+\mathrm{P}<0.10 ; * \mathrm{p}<0.05, * * \mathrm{p}<0.01, * * * \mathrm{p}<0.001$

Bold significantly different from USA results in fully interacted fixed effects model $(\mathrm{p}<0.05)$. 
While the lack of extra rooms depresses overall childbearing only in Greece, Portugal, and Spain, it depresses the fertility of the foreignborn in every country. Nevertheless, the negative effects of the crowding of the foreign-born on childbearing are attenuated by effect sizes, as per the interacted models in Table 5. As a result, despite encountering greater crowding than the native born in countries like Greece and Spain, the foreign-born are no more influenced by this crowding than the native born with respect to its effects on fertility. In Spain, this attenuation takes its strongest form, and the childbearing of the foreign-born seems to occur independently of the availability of extra rooms.

Those in the professional and managerial classes have greater access to extra rooms in every country. In the USA and Austria, the greater access of these higher status occupations to extra rooms, in conjunction with the stronger effect of having an extra room on fertility for the professional and managerial classes, results in substantial boosts to the likelihood of having children. In Greece, Portugal, and Spain, the greater access of the professional and managerial classes to extra rooms still does not allow them to average more than one extra room overall.

At country means, and given varying effects of roominess, the USA, Austria and Spain receive a substantial overall roominess bonus to their fertility rates relative to the more crowded countries of Greece and Portugal. American professionals have the largest roominess bonus to their fertility, followed by Austrian professionals. By contrast, in the USA, Austria, and Greece, the foreign-born receive a substantial roominess penalty on their fertility relative to the population average.

\section{Conclusion}

Overall, findings here suggest that residential roominess is a fairly powerful predictor of fertility for European and North American countries. As a result, the case can be made that new homeostatic mechanisms now link population density to fertility through the roominess of housing. These results fit well with a cultural theory that predicts important effects for residential roominess on fertility following the demographic transition. The influence of roominess (and by implication crowding) in demographic transition theorizing should be explored further.

In line with cultural theorizing, the professional and managerial classes are the most influenced by roominess, while the foreign-born tend to be the least influenced by roominess. This argues for developing more 


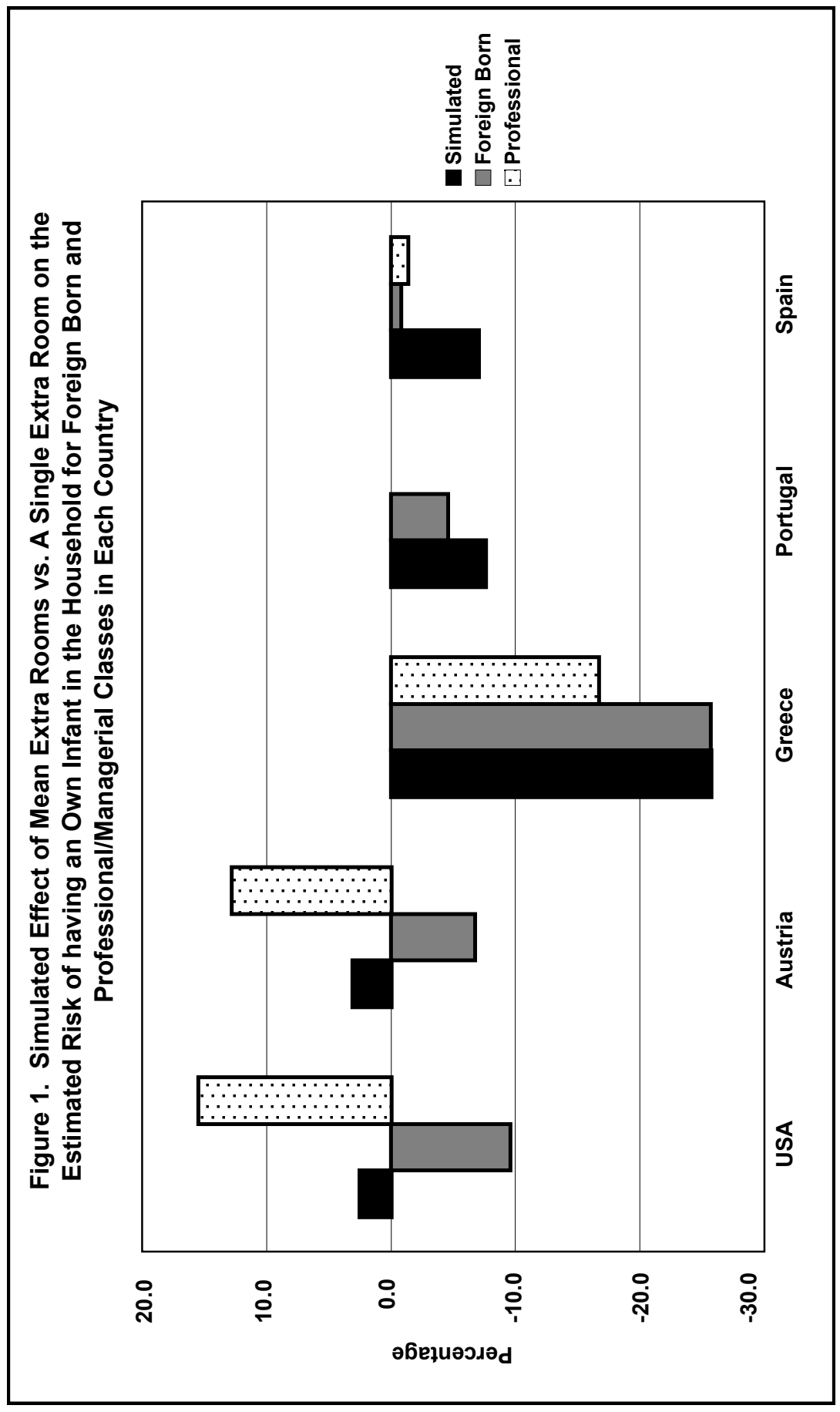

CSP 2010, 37.3-4: 475-496 492 
nuanced understandings of how class and culture operate together to orient people towards understandings of their social worlds. Class and culture are generative of contingent relationships between fertility and various explanatory factors of interest to demographers.

International differences in roominess seem to offer at least partial explanations for some, but not all, of the international variation in fertility. While the examination of differences in residential roominess offers to help explain differences in childbearing between the USA and many European countries, it cannot explain such differences between the USA and countries like Austria. Nor can differences in roominess explain the similarities in fertility between Austria, Spain, Portugal and Greece. Further explanations are required.

As a final note, I submit that the link between roomier dwellings and higher fertility is likely a causal relationship. The finer points of precedence here are not considered, for instance, tackling the thorny problem of distinguishing the timing of housing transitions and childbearing transitions, as in Mulder and Wagner (1998). People may move into their current housing before or after the arrival of the infants recorded in their households. However, it is suggested that people are forward thinking in both their housing and fertility decision-making, implicitly or explicitly linking these considerations together. The fact that roomy housing is often (though not always) more difficult to arrange or afford than the physical work of producing a child itself implies that the former is likely to have more effect on the latter than the other way around. In this, finding room in one's housing is an under-examined part of the larger task of finding room in one's life for a child. Nevertheless, future research might more carefully consider the relationship between residential roominess and childbearing in the life course, longitudinally considered, rather than at the cross-sectional, population level, as analyzed here. In this sort of modeling, it would be useful to estimate both current housing and the accessibility of roomier housing on the likelihood of pregnancy (see Lauster 2008, for an example of the latter).

The results here suggest that the positive association between roominess of housing and childbearing is widespread, but also culturally contingent. This has a variety of possible implications. Further explorations of the relationship between roominess and childbearing could help clarify and explain the mechanisms by which urbanization influences fertility. Likewise, the findings here suggest a strong role for housing policies in producing fertility outcomes. The differences in the effects of roominess on fertility between professional and managerial classes and the rest of the population point to the intriguing role of inequality and culture in the production of feelings of crowding. This finding is reinforced, as well, by the different effects of roominess 
between the foreign-born and native-born populations. Future investigations into the intersections of culture, inequality, and roominess are likely to produce many further insights into demographic phenomena like the widespread decline in fertility.

\section{Acknowledgement}

Responsibility for any errors rest with the author.

\section{References}

Curry, J. P. and G. Scriven. 1978. The relationship between apartment living and fertility for Blacks, Mexican-Americans, and other Americans in Racine, Wisconsin. Demography 15(4): 477-485.

Edwards, J, T. Fuller, S. Sermsri and S. Vorakitphokatorn. 1994. Why people feel crowded: An examination of objective and subjective crowding. Population and Environment 16(2): 149173.

Felson, M. and M. Solauns. 1975. The fertility-inhibiting effect of crowded apartment living in a tight housing market. American Journal of Sociology 80(6): 1410-1427.

Frykman, J. and O. Löfgren. 1987. Culture Builders: A Historical Anthropology of Everyday Life. New Brunswick, NJ: Rutgers University Press.

Fuller, T., J. Edwards, S. Vorakitphokatorn and S. Sermsri. 1996. Chronic stress and psychological well-being: Evidence from Thailand on household crowding. Social Science and Medicine 42(2): 265-280.

Gillis, J. 1996. A World of Their Own Making: Myth, Ritual and the Quest for Family Values. New York: Basic Books.

Goffman, E. 1959. The Presentation of Self in Everyday Life. New York: Anchor Books. 
Gove, W. R., M. Hughes and O. R. Galle. 1983. Overcrowding in the Household: An Analysis of Determinants and Effects. New York: Academic Press.

Krishnan, V. 1995. Effect of housing tenure on fertility. Sociological Spectrum 15(2): 117-129.

Kulu, H. and A. Vikat. 2008. Fertility differences by housing type: The effect of housing conditions or of selective moves? Demographic Research 17: 775-802.

Lauster, N. 2008. Better homes and families: Housing markets and young couple stability in Sweden. Journal of Marriage and Family 70(4): 891-903.

Lauster, N. and F. Tester. 2010. Culture as a problem in linking material inequality to health: On residential crowding in the Arctic. Health \& Place 16: 523-530.

Lee, R. 1987. Population dynamics of humans and other animals. Demography 24(4): 443-465.

Livi-Bacci, M. 2007. A Concise History of World Population. $4^{\text {th }}$ Edition. Malden, MA: Blackwell.

Malenfant, E. C. and A. Belanger. 2006. The fertility of visible minority women in Canada, in Report on the Demographic Situation in Canada, 2003 and 2004. Ottawa: Statistics Canada, pp. 79-96.

Minnesota Population Center. 2010. Integrated Public Use Microdata Series, International: Version 6.0 [Machine-readable database]. Minneapolis: University of Minnesota, 2010.

Mulder, C. and F. Billari. 2010. Home-ownership regimes and low fertility. Housing Studies 25(4): 527-541.

Mulder, C. and M. Wagner. 1998. First-time home-ownership in the family life-course: A West German-Dutch comparison. Urban Studies 35(4): 687-713. 
Mulder, C. and M. Wagner. 2001. The connections between family formation and first-time home ownership in the context of West Germany and the Netherlands. European Journal of Population 17: $137-164$

Murphy, M. and O. Sullivan. 1985. Housing tenure and family formation in contemporary Britain. European Journal of Population 1(3): 230-243.

Paydarfar, A. A. 1995. Effects of multi-family housing on marital fertility in Iran: population policy implications. Social Biology 42: $214-225$.

Population Reference Bureau. 2008. 2008 World Population Data Sheet. New York: PRB.

Simon, C. J. and R. Tamura. 2009. Do higher rents discourage fertility? Evidence from U.S. Cities, 1940-2000. Regional Science and Urban Economics 39: 33-42.

Ward, P. 1999. A History of Domestic Space: Privacy and the Canadian Home. Vancouver: UBC Press.

Watkins, S. 1990. From local to national communities: Transformations of demographic regimes in Western Europe, 1870-1960. Population and Development Review 16(2): 241-272. 